\title{
Neonatal Endotoxin Exposure Alters the Development of the Hypothalamic-Pituitary-Adrenal Axis: Early Illness and Later Responsivity to Stress
}

\author{
Nola Shanks, ${ }^{a}$ Sylvie Larocque, and Michael J. Meaney \\ Developmental Neuroendocrinology Laboratory, Douglas Hospital Research Centre, Departments of Psychiatry, and \\ Neurology and Neurosurgery, McGill University, Montreal, Canada H4H 1R3
}

The long-term consequences of neonatal endotoxin exposure on hypothalamic-pituitary-adrenal axis (HPA) function were assessed in adult female and male Long-Evans rats. At 3 and $5 \mathrm{~d}$ of age, pups were administered endotoxin (Salmonella enteritidis, $0.05 \mathrm{mg} / \mathbf{k g}$, i.p.) at a dose that provokes a rapid and sustained physiological response, but with no mortality. As adults, neonatally endotoxin-treated animals exhibited significantly greater adrenocorticotrophic hormone (ACTH) and corticosterone responses to restraint stress than controls. In addition, dexamethasone pretreatment was less effective in suppressing ACTH responses to restraint stress in endotoxin-treated animals than in controls, suggesting decreased negative-feedback sensitivity to glucocorticoids. Neonatal endotoxin treatment elevated restingstate median eminence levels of corticotropin-releasing hormone (CRH) and arginine vasopressin in adult male animals, and arginine vasopressin in both adult males and females. Neonatal exposure to endotoxin also increased CRH mRNA expression in the paraventricular nucleus of the hypothalamus of adult males, with no difference in females. Finally, glucocorticoid receptor density was reduced across a wide range of brain regions in the neonatal endotoxintreated, adult animals. These data illustrate the interactive nature of immune and endocrine systems during development. It appears that endotoxin exposure during critical stages of development decreases glucocorticoid negativefeedback inhibition of ACTH secretagogue synthesis, thus increasing HPA responsiveness to stress. The implication of these findings is that exposure to gram-negative LPS in early life can alter the development of neural systems which govern endocrine responses to stress and may thereby predispose individuals to stress-related pathology.

IKey words: hypothalamic-pituitary-adrenal axis, devel-

\footnotetext{
Received Feb. 28, 1994; revised June 6, 1994; accepted June 23, 1994.

This research was supported by a grant from the Medical Research Council of Canada (MRCC) to M.J.M., who holds an MRCC Scientist award. N.S. was supported by a postdoctoral fellowship from the Natural Sciences and Engineering Research Council of Canada, and is currently an MRCC Fellow in the Clinical Immunopathology Laboratory, University of Pittsburgh Medical Center. We thank Dr. Jonathan Seckl for his comments on an earlier draft.

Correspondence should be addressed to Michael J. Meaney, Douglas Hospital Research Center, 6875 Boulevard LaSalle, Montréal (Québec), Canada H4H I R3.

a Present address: Clinical Immunopathology Laboratory, University of Pittsburgh Medical Center, Pittsburgh, PA.
}

Copyright (C) 1995 Society for Neuroscience $0270-6474 / 95 / 150376-09 \$ 05.00 / 0$ opment, endotoxin, adrenocorticotropin, corticotropin-releasing factor (hormone), vasopressin]

There are considerable individual differences in the response of the hypothalamic-pituitary-adrenal (HPA) axis to stress and these differences appear to be related to vulnerability to several forms of pathology (see Chrousos and Gold, 1992; McEwen and Steller, 1993). The variability in HPA responses to stress derives from organismic variables such as sex, reproductive state, and age, as well as genetic background (e.g., Le Mevel et al., 1979; Sapolsky et al., 1984; Shanks et al., 1990; Walker et al., 1990, 1992; Viau and Meaney, 1991; Meaney et al., 1993). In addition, postnatal environmental events are known to alter the development of the HPA response to stress (Levine, 1957, 1962; Levine et al., 1967; Ader and Grota, 1969; Meaney et al., 1988, 1989; Plotsky and Meaney, 1993; Viau et al., 1993). For example, as adults, neonatally handled animals exhibit dampened HPA responses to stress compared with nonhandled animals (Levine, 1957, 1962; Hess et al., 1969; Meaney et al., 1988, 1989; Viau et al., 1993). In contrast, adult animals exposed to repeated periods of prolonged maternal separation as neonates display increased HPA responses to stress (Plotsky and Meaney, 1993). These effects persist throughout the life of the animal and the resulting differences in HPA activity are associated with altered T-dependent antibody responses (Bhatnagar et al., 1992) and the incidence of age-related neuropathology (Meaney et al., 1988).

Immune activation elicits both HPA and central catecholamine alterations similar to those seen following stress (Blalock, 1984; Dunn et al., 1987, 1989; Zalcman et al., 1991; Anisman et al., 1993; Rivier et al., 1993; Stenzel-Poore et al., 1993). Furthermore, the immune and HPA systems are mutually regulatory, and these interactions partly determine the impact of stress on immune functioning (Munck et al., 1984; Irwin et al., 1990; Berkenbosch et al., 1991; Anisman et al., 1993; Rivier et al., 1993). Given the close, functional association between the HPA axis and immune system, we wondered whether endotoxin exposure and subsequent exposure to immune factors associated with acute phase responses during early life might alter the development of the HPA axis. Endotoxin administration reliably activates HPA responding in the neonate, and this effect appears to be mediated by corticotropin-releasing hormone (CRH) release (Witek-Janusek, 1988; Shanks and Meaney, in press $\mathrm{a}, \mathrm{b})$. Considcring the immunc-HPA interactions early in postnatal life, when HPA development is susceptible to envi- 
ronmental influences, it seems interesting to ask whether such interactions might permanently alter HPA development. This question is potentially of considerable importance since early postnatal life in mammals represents a period of considerable bacterial colonization (largely in the nasopharynx, intestine, and vagina), and the newborn is very susceptible to infection (see Williams, 1981).

There are limited data indicating long-term consequences following endocrine-immune interactions during the first week of life. In particular, it has been demonstrated that early endocrine events have considerable impact on immune development of tolerance (Pierpaoli, 1981). Conversely, immune challenge during the first week of life with Newcastle Disease virus is associated with alterations in both gonadal and adrenal weights (O'Grady and Hall, 1991). These data indicate that endocrine and immune processes probably develop dependently; however, to the best of our knowledge little or nothing is known about early exposure to endotoxin and its long-term effects on neural control of endocrine function.

In the present studies we examined the effects of postnatal endotoxin exposure on the development of the HPA axis in male and female rats. We have used a dose of Salmonella enteritidis sufficiently low so as to not produce any mortality (see Shanks et al., in press a). Nevertheless, this endotoxin dose provokes an HPA response, increased blood glucose levels, and results in greatly reduced behavioral activity (see Witek-Janusek, 1988; Shanks et al., in press a,b). Animals were treated during the first week of life, a period during which environmental events such as handling or maternal separation have been found to permanently alter HPA development (references cited above). Animals were then left untreated and examined at 4-5 months of age as sexually mature, adult animals. The results of these studies show that exposure to gram-negative LPS in early life can permanently alter the development of neural systems which govern endocrine responses to stress.

\section{Materials and Methods}

Animals. Pregnant Long-Evans dams were received from Charles River, St. Constant, Québec at $18 \mathrm{~d}$ gestation. Litters were randomly assigned to the different experimental groups (four litters per group), and litter size varied between $12-15$ pups. Rat pups were injected intraperitoneally on days 3 and 5 of life with either $0.05 \mathrm{mg} / \mathrm{kg}$ Salmonella enteritidis endotoxin (Sigma, St. Louis, MO) in sterile saline (injection volume not exceeding $0.1 \mathrm{cc}$ ) or an equivalent volume of sterile saline vehicle, or were left untreated. We previously determined that HPA responding in the neonate following a single endotoxin injection was elevated for slightly less than $48 \mathrm{hr}$ (Shanks and Meaney, in press a); therefore, we injected the animals twice during the first week (days 3 and 5 of life) to provoke immune activation for days 3-7 of life.

On day 22 of life the animals were weaned and housed in same-sex, same-treatment groups of three animals per cage. Animals were maintained on a 12:12 light: dark schedule (lights on at $0800 \mathrm{hr}$ ) with free access to food (Purina Lab Chow) and water. The animals used in these experiments were $4--5$ months of age $(350-400 \mathrm{gm})$ at the time of testing. All testing was performed during the light phase of the cycle between 12:00 and 15:00 hr.

Adrenalectomy was performed under metophane (Methoxyflurane; Pitman-Moore, Inc., Washington Crossing, NJ) anesthesia and all adrenalectomized animals were provided with $0.9 \%$ saline as drinking water. For studies of resting-state median eminence peptide content, animals were rapidly (i.e., $<10 \mathrm{sec}$ ) killed by decapitation following removal from the home cage between 11:00 and 13:00 hr. All procedures were conducted in accordance with the guidelines of the Canadian Council on Animal Care and the McGill University Animal Care Committee.

Stress testing and blood sampling. Three days prior to testing, animals were implanted with indwelling jugular catheters under Metophane anesthesia and single housed for the remainder of the study (see Viau et al., 1993). Restraint stress was performed using tubular, plastic restrainers lined with foam rubber. The animals were placed into the restrainers for a $20 \mathrm{~min}$ period. A blood sample $(\sim 300 \mu 1)$ was taken immediately before the animal was placed into the restrainer and less than $10 \mathrm{sec}$ following removal from the home cage. This sample was used to obtain estimates of basal ACTH and B levels prior to stress. Blood samples $(\sim 150 \mu \mathrm{l})$ were then taken from the same animals via a jugular catheter at various times during restraint.

In one experiment animals were injected subcutaneously with $10 \mu \mathrm{g}$ $\mathrm{kg}$ dexamethasone (in ETOH: saline/1:9) or vehicle $3 \mathrm{hr}$ prior to restraint testing in order to examine glucocorticoid negative-feedback effects. In this experiment, blood samples were taken prior to and at 10 and $20 \mathrm{~min}$ of restraint. This dose of dexamethasone was chosen on the basis of previous dose-response studies using this same procedure (Meaney et al., 1989) to define differences in glucocorticoid negativefeedback sensitivity between handled and nonhandled rats.

Blood samples for corticosterone or corticosteroid-binding globulin (CBG) measurements were taken in heparinized tubes, placed on ice, centrifuged, and stored at $-30^{\circ} \mathrm{C}$ until assayed. Blood samples for ACTH assays were taken in tubes containing EDTA and Trasylol. Samples were centrifuged and stored at $-80^{\circ} \mathrm{C}$.

Radioimmunoassays. Plasma corticosterone was measured by the radioimmunoassay of Krey et al. (1975) with a highly specific corticosterone antiserum (B3-163, Endocrine Sciences, Tarzana CA), ${ }^{3} \mathrm{H}$-corticosterone $(101 \mathrm{Ci} / \mathrm{mmol}$, New England Nuclear, Boston, MA), as tracer, and $1 \mu \mathrm{l}$ of plasma. The minimum level of detection with the assay was $5 \mathrm{pg} / \mathrm{ml}$. The antiserum crossreacts slightly with desoxycorticosterone $(\sim 4 \%)$, but not with cortisol $(<1 \%)$. The intra- and interassay coefficients of variation were 8.9 and $11.2 \%$, respectively.

Plasma $(25 \mu \mathrm{l})$ ACTH was measured by the radioimmunoassay described by Walker et al. (1990) with an ACTH antiserum (IgG Corp., Nashville, TN) and ${ }^{125} \mathrm{I}$-ACTH (Incstar, Stillwater, MN) as tracer. The ACTH antibody crossreacts $100 \%$ with $\mathrm{ACTH}_{1-39}, \mathrm{ACTH}_{1-18}$, and $\mathrm{ACTH}_{1-24}$, but less than $1 \%$ with $\mathrm{ACTH}_{1-16}, \beta$ - endorphin, $\alpha$-/and $\beta$-MSH, and $\alpha$-/and $\beta$-lipotropin. The intra- and interassay coefficients of variation were 11 and $8 \%$, respectively. The minimal detectable level was $10 \mathrm{pg} / \mathrm{ml}$.

Determination of median eminence content for CRH and AVP was performed using an acid extraction procedure (see Suda et al., 1983). Median eminence samples were homogenized by sonication in $0.1 \mathrm{~N}$ $\mathrm{HCl}$ with $0.001 \% \beta$ - mercaptoethanol, $0.5 \%$ ascorbic acid, $0.01 \%$ bacitracin, and $0.001 \%$ phenylmethylsulfonylfluoride. Extracts were then centrifuged at $12,000 \mathrm{~g}$ for $30 \mathrm{~min}$ and aliquots of the extract were evaporated. Extracts were reconstituted with assay buffer and peptide levels were determined using radioimmunoassays (see Plotsky, 1985) with $\mathrm{CRH}$ and AVP antibodies (Peninsula Laboratories Inc., Belmont, $\mathrm{CA}$ ) and ${ }^{125}$ - CRH and ${ }^{125}$-AVP as tracers. The $\mathrm{CRH}$ antibody crossreacts $100 \%$ with rat and human CRH, while the AVP antibody crossreacts $100 \%$ with $\left[\mathrm{ARG}^{8}\right]$-vasopressin. Sensitivity of the CRH and AVP assays was $15 \mathrm{pg} /$ tube and $4 \mathrm{pg} /$ tube, respectively. Intra- and interassay variability was 2.4 and $4.0 \%$ for $\mathrm{CRH}$ and 3.1 and $6.2 \%$ for AVP. Protein levels were determined using an aliquot of the extract that was taken prior to centrifugation with the method of Bradford (1976). Values are expressed as $\mathrm{pg} / \mu \mathrm{g}$ protein.

Plasma CBG. Plasma CBG levels were determined by single-point assays using the method of Martin et al. (1975), with slight modifications (see Meaney et al., 1992). Plasma samples $(20 \mu \mathrm{l})$ were stripped of endogenous corticosterone using a $10 \times 1 \mathrm{~cm}$ Sephadex LH-20 column and the plasma was diluted 1:50 with TEDGM (30 mM Tris, $1 \mathrm{~mm}$ EDTA, $10 \mathrm{~mm}$ sodium molybdate, $10 \% \mathrm{v} / \mathrm{v}$ glycerol, and $1 \mathrm{~mm}$ dithiothreitol; $\mathrm{pH}$ at 7.4$)$. Aliquots $(225 \mu 1)$ of the diluted plasma were then incubated in buffer $(150 \mu \mathrm{l})$ containing a saturating $80 \mathrm{nM}$ concentration of ${ }^{3} \mathrm{H}$-corticosterone for $90 \mathrm{~min}$ at $2-4^{\circ} \mathrm{C}$ (see Martin et al., 1975). Nonspecific binding was defined in parallel incubations by a 200 -fold excess of cold corticosterone. Separation of bound from free was achieved using Sephadex LH-20 columns $(4 \times 1 \mathrm{~cm})$, equilibrated with TEDGM, made from disposable pipette tips. Following the incubation, $100 \mu \mathrm{l}$ of the incubates were washed into the columns with $100 \mu$ of TEDGM. The columns were eluted $30 \mathrm{~min}$ later with $500 \mu$ l of TEGM into minivials, which were then filled with $5 \mathrm{ml}$ of Liquiscent (National Diagnostics, Somcrville, NJ), and countcd in a Packard scintillation counter at $60 \%$ efficiency. Protein content was determined by the method of Bradford (1976) and the results were expressed as picomols (pmols) ${ }^{3} \mathrm{H}$-corticosterone binding/mg protein.

Glucocorticoid receptor binding. Adrenalectomy was performed $16 \mathrm{hr}$ 

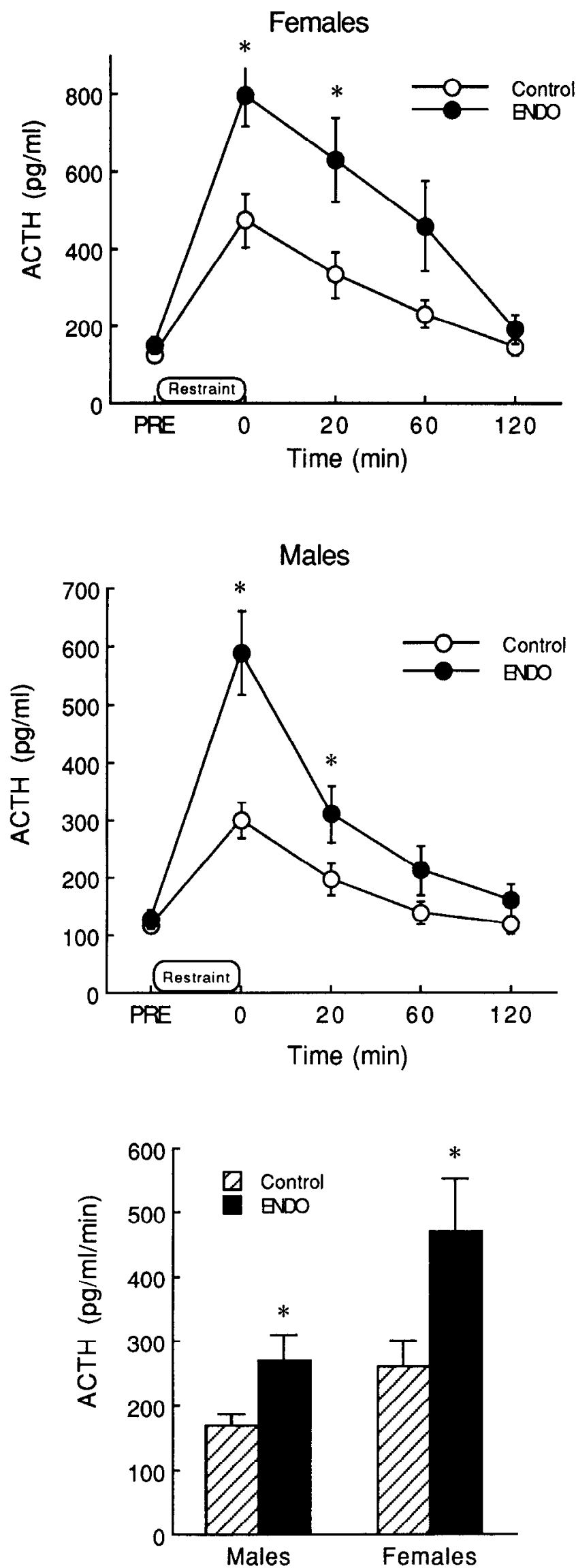

prior to death to ensure clearance of endogenous steroid (see McEwen et al., 1986). Animals were killed by rapid decapitation and tissues collected for subsequent glucocorticoid receptor-binding determinations. Brains were removed quickly, then placed on ice, and the frontal cortex, hippocampus, and hypothalamus dissected, then frozen at $-80^{\circ} \mathrm{C}$ until assayed.

The tissue was homogenized in TEDGM (pH adjusted to 7.4). The homogenate was then centrifuged at $2^{\circ} \mathrm{C}$ for $60 \mathrm{~min}$ at $105,000 \times \mathrm{g}$. Aliquots of the soluble fraction were incubated with a saturating $10 \mathrm{~nm}$ concentration of ${ }^{3} \mathrm{H}$-dexamethasone and nonspecific binding was determined in a parallel set of incubates containing a 500-fold excess of unlabeled RU 28362. RU 28362 has been shown to selectively bind to the glucocorticoid receptor, showing very little affinity for the mineralocorticoid receptor (see Reul and DeKloet, 1985; McEwen et al., 1986) Thus, these binding conditions define glucocorticoid receptor density.

Separation of bound from free radioligand was achieved using Sephadex LH-20 columns $(4 \times 1 \mathrm{~cm})$ made from disposable pipette tips and cquilibratcd with TEDGM. Following incubation, $100 \mu \mathrm{l}$ of the incubate was washed into the columns with $100 \mu \mathrm{l}$ of TEDGM. The columns were eluted 30 min later with $500 \mu$ l of TEGM into minivials, which were then filled with scintillation cocktail and counted in a Packard scintillation $\beta$ counter at an efficiency of $40 \%$. Protein content of the supernatants was determined using the method of Bradford (1976) and results expressed as fmols bound ${ }^{3} \mathrm{H}$-dexamethasone/mg protein specific binding.

$C R H m R N A$ in situ hybridization. Following rapid decapitation, brains were removed and frozen quickly in isopentane. Brains were blocked and $15 \mu \mathrm{m}$ cryostat slices were mounted on polylysine-coated slides, dessicated under a vacuum at room temperature, then stored at $-80^{\circ} \mathrm{C}$. Preparation of the CRH mRNA riboprobe as well as the in situ hybridization procedure have been previously described (see Watts and Swanson, 1989). CRH mRNA in situ hybridization was performed using a probe generously provided by Dr. Kelly Mayo (Northwestern University). The probe was constructed from a $380 \mathrm{bp}$ PvuII to SphI fragment ligated into pGEM-4. The insert corresponds to the C-terminus of the preproCRH molecule that includes the entire CRH peptide. Slides were warmed to room temperature, then postfixed in $4 \%$ paraformaldehyde in $0.1 \mathrm{M}$ phosphate buffer $(\mathrm{pH} 7.0$ ) for $10 \mathrm{~min}$ at room temperature, and washed in three changes of $2 \times \operatorname{SSC~}(0.3 \mathrm{M} \mathrm{NaCl}, 0.03 \mathrm{M}$ sodium citrate) in sterile water containing $0.02 \%$ diethylpyrocarbonate (Depc $\mathrm{H}_{2} \mathrm{O}$ ). Hybridization was performed at $45^{\circ} \mathrm{C}$ for $16-20 \mathrm{hr}$ in buffer containing $50 \%$ formamide, $600 \mathrm{~mm} \mathrm{NaCl}, 10 \mathrm{~mm}$ Tris (pH 7.5), $1 \mathrm{~mm}$ EDTA, $0.02 \%$ Ficoll, $0.02 \%$ polyvinylpyrrolidone, $0.1 \%$ bovine serum albumin, $20 \mu \mathrm{g} / \mathrm{ml}$ denatured salmon sperm DNA, $25 \mu \mathrm{g} / \mathrm{ml}$ yeast tRNA, $10 \%$ dextran sulphate, $10 \mathrm{~mm}$ dithiothreitol, and $2 \times 10^{7} \mathrm{CPM} / \mathrm{ml}$ of ${ }^{35} \mathrm{~S}$-UTP-labcled cRNA antisense probe. Slides were rinsed in $2 \times \mathrm{SSC}$, treated with RNAse I ( $30 \mu \mathrm{g} / \mathrm{ml}$; Pharmacia) for $30 \mathrm{~min}$ at room temperature, then rinsed again in $2 \times \mathrm{SSC}$, and washed in a final stringency of $0.1 \mathrm{SSC}$ (containing $14 \mathrm{mM} \beta$-mercaptoethanol) for $60 \mathrm{~min}$ at $60^{\circ} \mathrm{C}$. Sections were then dehydrated with increasing concentrations of ethanol ( $0.3 \mathrm{M}$ sodium acetate), dried, and exposed to $\beta$-max Hyperfilm (Amersham) for $10 \mathrm{~d}$.

CRH mRNA expression was determined using integrated optical density measurements from the $\beta$-max Hyperfilm (see Watts and Swanson, 1989). Measures were taken from slides bearing the maximal extent of the parvocellular region of the PVN (ppPVN), as determined by adjacent Nissl-stained sections. The optical density of CRH mRNA hybridization in left and right ppPVN for each animal was measured using an image analysis system and the average was calculated after subtracting background.

Statistical analysis. The hormone data were analyzed using an analysis of variance model with one repeated measure (time) and Scheffe post hoc analysis. Integrated hormone levels (area under the curve) were calculated using the Trapezoidal rule. Analysis of between groups differences was performed using $t$ tests.

We performed a preliminary analysis on the data from saline and untreated animals and found that these animals did not differ on any measure ( $p>0.5$ for all comparisons). This finding is consistent with

$\longleftarrow$

Figure 1. Mean ( \pm SEM) plasma ACTH levels in control and neonatal endotoxin-treated (ENDO) animals prior to, during, and following a 20 min period of restraint stress. The bottom frame shows integrated plasma ACTH responses to stress in these groups $(n=8-10 /$ group $) .{ }^{*}$ Indicates significant group difference, $p<0.05$. 
our previous studies showing that animals receiving one or two injections as neonates do not differ from untreated controls on measures of adult HPA function (see Meaney et al., 1987). Hence, the data from these groups was pooled and is presented as a single control group.

\section{Results}

Stress responding

Plasma ACTH and corticosterone responses to $20 \mathrm{~min}$ of restraint stress were significantly higher in neonatally endotoxintreated animals compared with controls (Figs. 1 and 2). There were no differences in prestress measures of either ACTH or corticosterone (Figs. 1 and 2). Thus, differences in HPA responses to stress were not associated with differences in prestress, basal glucocorticoid levels. For both females and males, endotoxin-treated animals showed significantly higher peak plasma ACTH levels during restraint and at 20 min following the termination of restraint (Fig. 1). Plasma ACTH levels remained elevated at $60 \mathrm{~min}$ in the endotoxin-treated animals; however, this difference was not significant. As expected on the basis of these differences, the integrated plasma ACTH response to restraint was substantially (almost twofold) higher in the male and female endotoxin-treated animals (Fig. 1).

Peak responses of plasma corticosterone to restraint were significantly higher in male, but not female, endotoxin-treated treated animals (Fig. 2). However, plasma corticosterone responses in the poststress period were higher in both male and female endotoxin-treated animals, reflecting the differences in plasma ACTH levels. Plasma corticosterone levels remained elevated to a greater extent in females than in males. Analysis of the plasma corticosterone responses showed that integrated corticosterone response to restraint stress was significantly higher in the both male and female neonatal endotoxin-treated animals (Fig. 2). Thus, the corticosterone data paralleled that for plasma ACTH. In addition, we calculated ACTH : corticosterone ratios and found no differences across the groups (data not shown). This suggests that there were no effects on adrenal sensitivity to ACTH.

\section{Plasma CBG levels}

Mean plasma CBG levels (pmols bound ${ }^{3} \mathrm{H}$-corticosterone/mg protein) did not differ as a function of neonatal endotoxin treatment for either males (controls $=7.1 \pm 0.5$, endotoxin treated $=7.6 \pm 0.7 \mathrm{pmol} / \mathrm{mg}$ protein) or females (controls $=17.2 \pm$ 1.0 , endotoxin treated $=16.4 \pm 0.8 \mathrm{pmol} / \mathrm{mg}$ protein). However, as previously reported (e.g., Gala and Westphal, 1965), females had significantly $(p<0.0001)$ higher levels of plasma CBG than did males. The free corticosterone signal is proportional to the non-CBG bound fraction of the circulating hormone (Pardridge et al., 1983). Thus, the absence of any difference in plasma CBG between the endotoxin-treated and control groups suggests that the total corticosterone levels accurately reflected the differences in free hormone levels.

\section{Median eminence $C R H$ and $A V P$ levels, and PVN levels of CRH mRNA expression}

Neonatal endotoxin treatment resulted in long-term changes in resting-state levels of ACTH secretagogues in the median eminence. However, the pattern of these effects depended upon gender. Among males, resting levels of median eminence CRH content were significantly elevated in endotoxin-treated animals (Fig. 3). This effect was not observed in females. In contrast, median eminence AVP levels were significantly higher in both
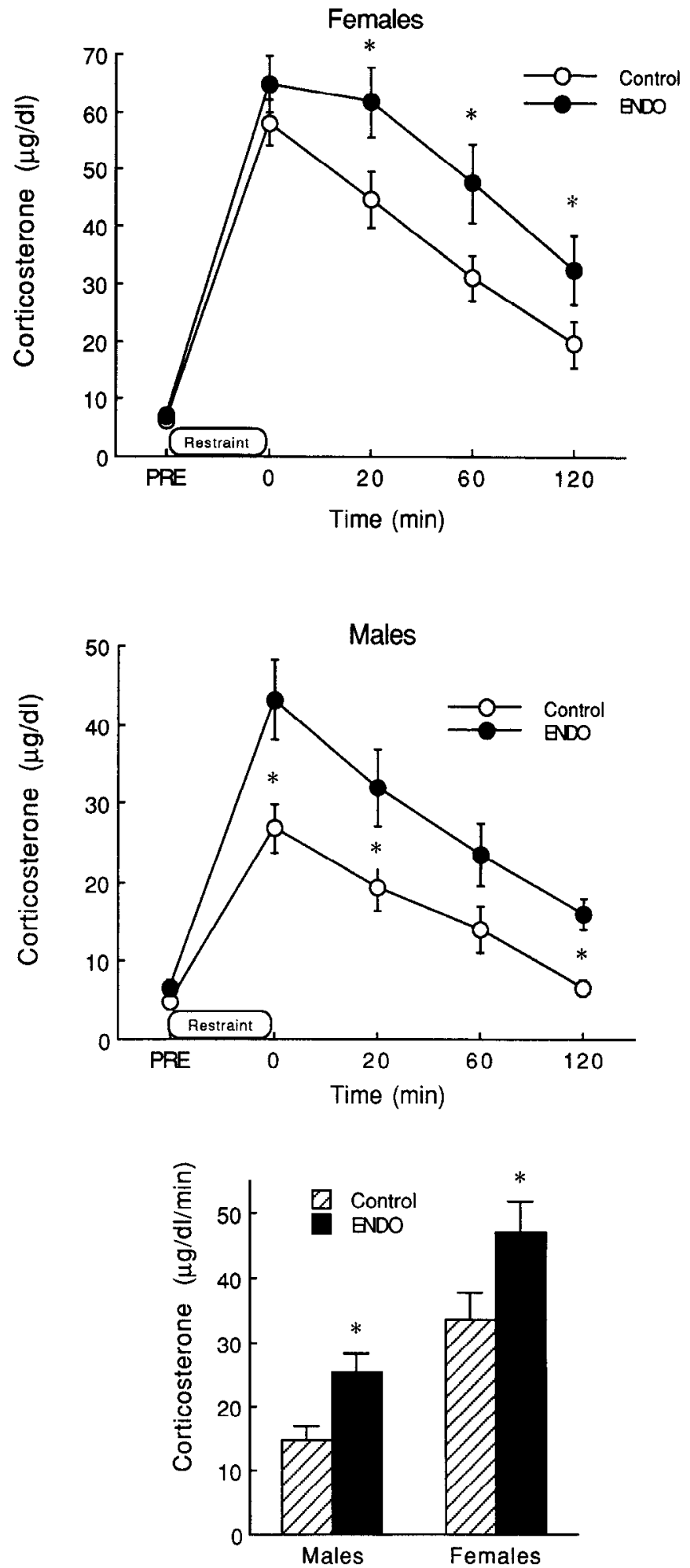

Figure 2. Mean $( \pm \mathrm{SEM})$ plasma corticosterone levels in control and neonatal endotoxin-treated $(E N D O)$ animals prior to, during, and following a 20 min period of restraint stress. The bottom frame shows integrated plasma corticosterone responses to stress in these groups ( $n$ $=8-10$ /group). ${ }^{*}$ Indicates significant group difference, $p<0.05$.

male and female neonatal endotoxin-treated animals compared with controls (Fig. 3).

The analysis of the autoradiograms revealed significantly increased CRH mRNA levels in male endotoxin-treated animals 

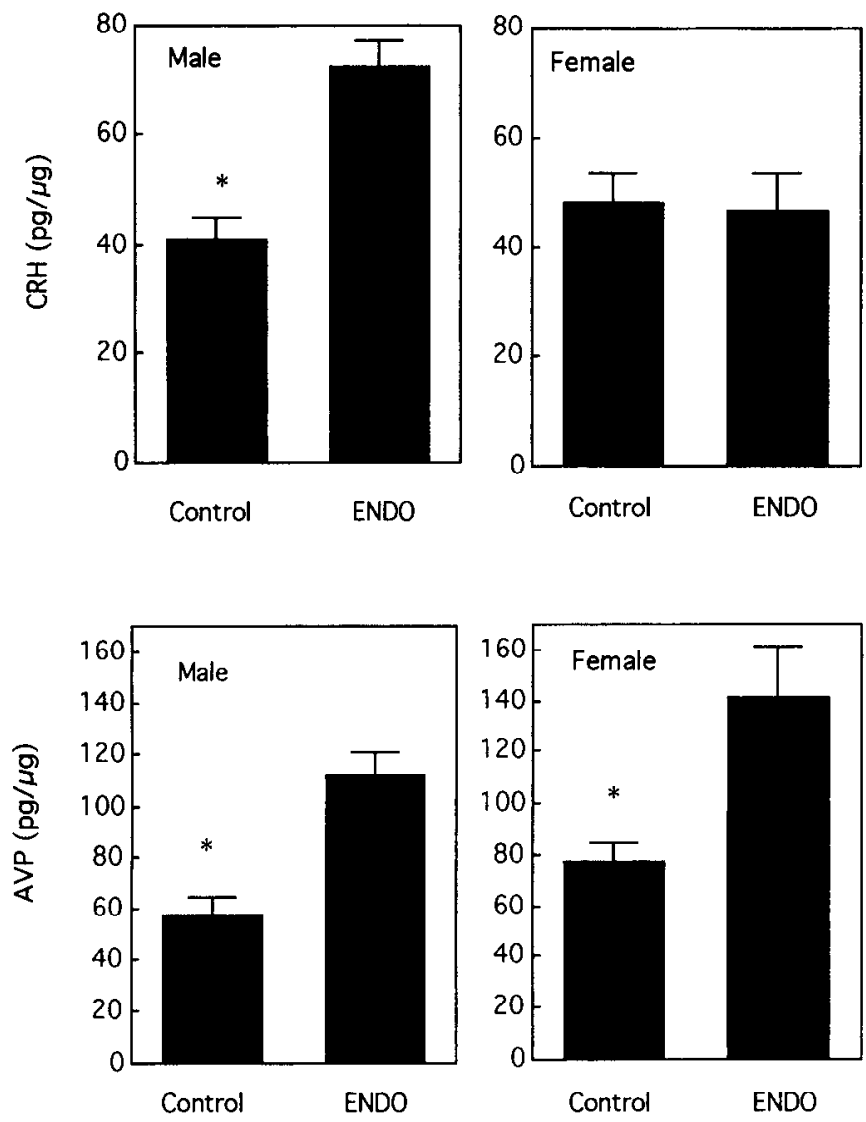

Figure 3. Mean ( \pm SEM) levels $(\mu \mathrm{g} / \mathrm{mg}$ protein) of median eminence CRH (top) and AVP (bottom) in control and neonatal endotoxin-treated $(E N D O)$ animals $(n=7-8 /$ group). *Indicates significant group difference, $p<0.001$.

compared with controls (Fig. 4). However, consistent with the measures of median eminence peptide content, there was no difference in CRH mRNA expression between endotoxin-treated and control females.

\section{Dexamethasone suppression of plasma ACTH responses to restraint stress}

As expected, plasma ACTH responses to restraint stress were significantly greater in the saline-pretreated, endotoxin-treated animals compared with saline-pretreated controls (Fig. 5, and note the differences in the range of values for the ordinates). Moreover, there were substantial differences in the response of the neonatal endotoxin-treated and control animals to dexamethasone pretreatment. Restraint-induced elevations in plasma ACTH were effectively suppressed by dexamethasone pretreatment in both male and female control animals. Thus, plasma ACTH levels in dexamethasone-pretreated control animals did not differ from basal values at either 10 or 20 min of restraint. At both time points, plasma ACTH levels were significantly lower in the dexamethasone-pretreated controls compared with saline-pretreated controls.

In contrast, dexamethasone pretreatment reduced, but did not eliminate, restraint-induced increases in plasma ACTH in neonatal endotoxin-treated animals. In the endotoxin-treated animals, both dexamethasone- and saline-pretreated animals showed significant plasma ACTH responses to restraint (i.e., significantly greater than basal ACTH level; Fig. 5). Overall, the plasma ACTH responses were somewhat decreased following

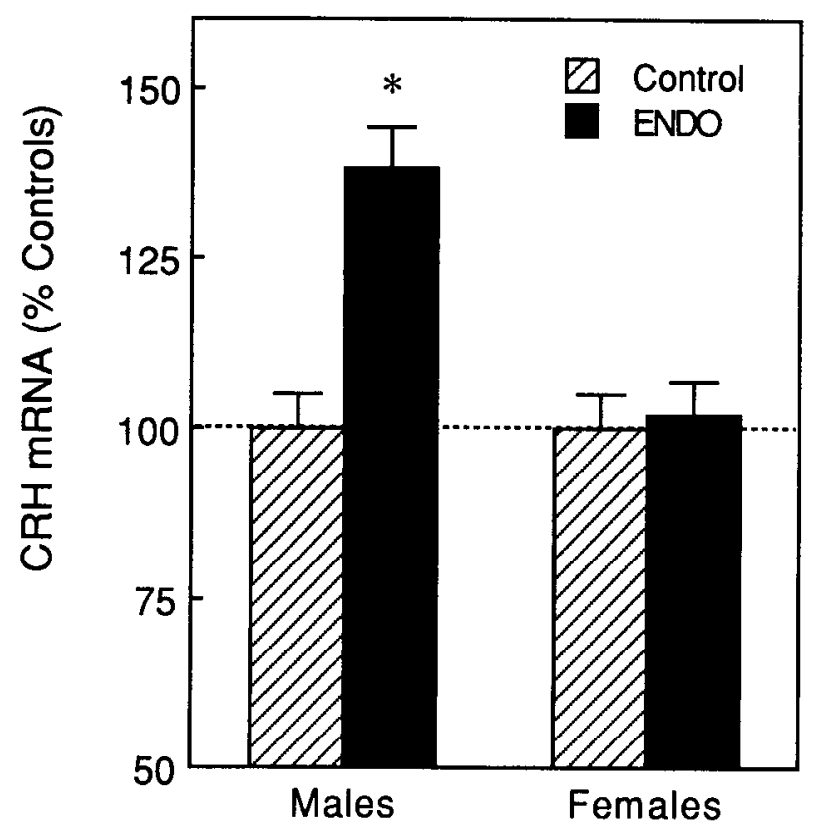

Figure 4. Mean $( \pm$ SEM) levels of CRH mRNA expression in control and neonatal endotoxin-treated animals as a percentage of the control values (mean for control group $=100 \%$ ). The raw data were derived from optical density measurements of autoradiograms following in situ hybridization ( $n=5$ /group). *Indicates significant group difference, $p$ $<0.001$.

dexamethasone pretreatment in endotoxin-treated rats; however, plasma $\Lambda C T H$ levels were significantly diffcrent from saline-pretreated animals only at $20 \mathrm{~min}$ into restraint in the female animals. While dexamethasone pretreatment reduced plasma ACTH responses to restraint stress in both groups, this effect was more marked in the control animals. These data indicate that glucocorticoid negative feedback is less effective in the neonatal endotoxin-treated animals.

\section{Glucocorticoid receptor binding}

As indicated in Table 1, neonatal endotoxin treatment decreased glucocorticoid receptor density in the hypothalamus, hippocampus, and frontal cortex of adult animals, regions known to regulate HPA responses to stress. These differences were in the range of $20-30 \%$ decreases in the endotoxin-treated rats. Overall the effect was significantly decreased glucocorticoid receptor sites in the forebrain of endotoxin-treated animals compared with controls.

\section{Discussion}

Endotoxin exposure during the first week of life altered the development of the HPA axis. In comparison to controls, neonatally endotoxin-trcatcd animals secreted higher levels of ACTH and corticosterone in response to stress and increased restingstate median eminence levels of CRH (in males) and of AVP (in both males and females). In addition, CRH mRNA expression in the PVN was increased in endotoxin-treated males compared with controls. The effects on CRH and AVP levels most likely reflect differences in readily releasable storage pools of these peptides in axon terminals located in the median eminence. Thus, a stress-related excitatory signal at the level of the 

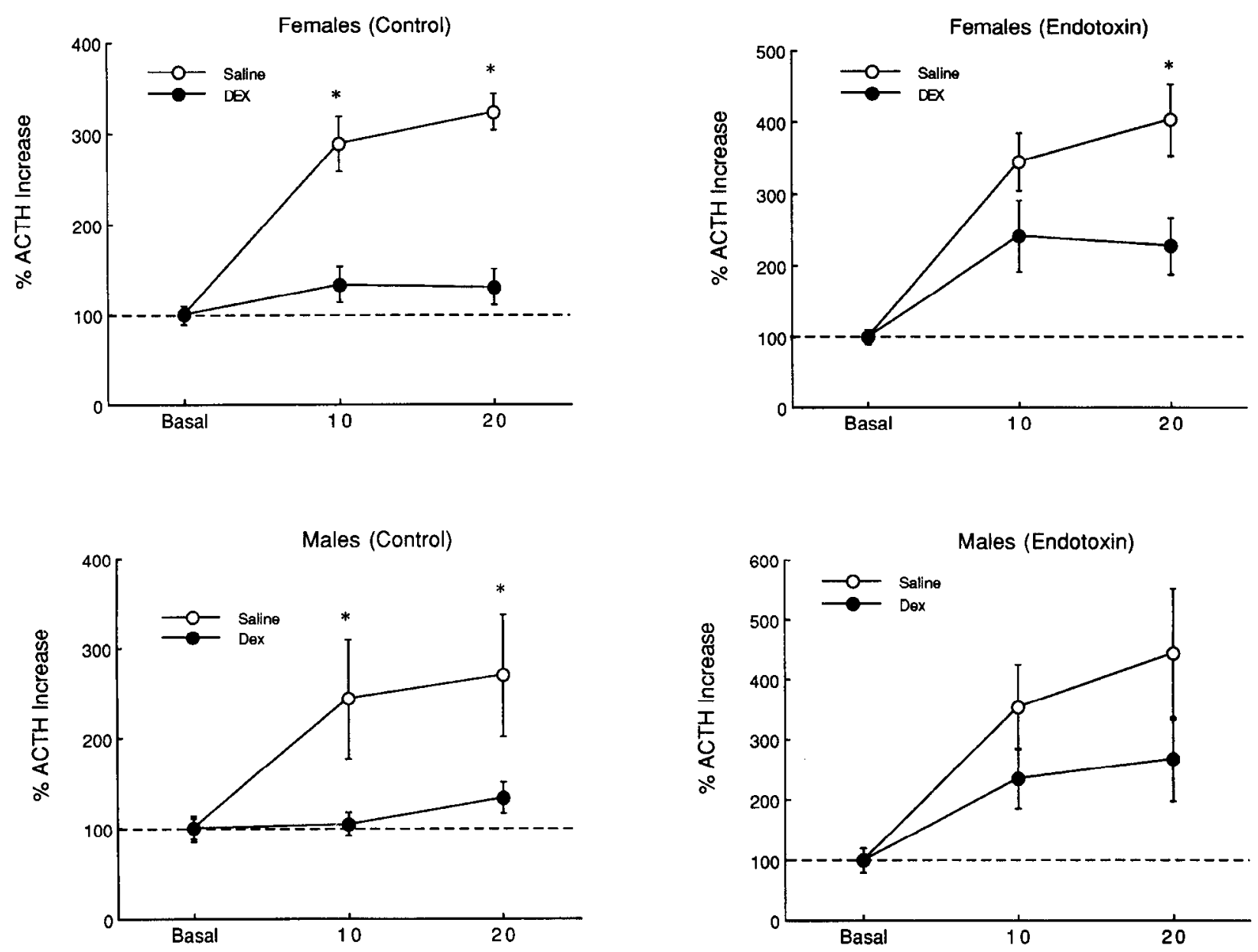

Figure 5. Mean ( \pm SEM) plasma ACTH levels at 10 or 20 min following the onset of restraint stress in control and neonatal endotoxin-treated $(E N D O)$ animals. The data are expressed as the percentage of basal ACTH levels for each group, thus showing the magnitude of the stress-induced increase in plasma ACTH ( $n=6-8 /$ group). Animals were pretreated $3 \mathrm{hr}$ prior to testing with either saline or dexamethasone $(10 \mu \mathrm{g} / \mathrm{kg}$; $\mathrm{DEX})$. *Indicates significant group difference, $p<0.001$.

hypothalamus likely results in greater CRH and AVP release in the endotoxin-treated animals and, in turn, a greater plasma ACTH signal. Although the increased stress-induced release of CRH/AVP from PVN neurons of neonatal endotoxin-treated animals remains to be confirmed, this idea is consistent with the findings that median eminence CRH (e.g., Murakami et al., 1989) and AVP (Viau et al., submitted) levels are strongly correlated with $\mathrm{ACTH}$ responses to restraint stress. Indeed, the differences in the terminal pools of CRH and AVP suggest that cndotoxin-trcated and control animals would differ in stressors mediated by either secretagogue. Note, pituitary ACTH responses to restraint stress are mediated by dynamic variations in both CRH and AVP (Linton et al., 1985; Nakane et al., 1985).

Although median eminence levels of AVP were elevated in both male and female endotoxin-treated animals, the effect on $\mathrm{CRH}$ levels was observed only in males. This was true both for median eminence peptide content and for mRNA levels. It is not clear why the effect of early endotoxin treatment on measures of CRH synthesis was not observed in females. However, hypothalamic CRH mRNA and median eminence CRH levels in female rats have been shown to vary considerably over the estrus cycle (Hiroshige and Wada-Okada, 1973). In the present study, the estrus state of the females was not controlled, and it may be that the effects of the early endotoxin treatment were shrouded by those associated with the changes in the estrus cycle.
Otherwise, we really have no explanation for this finding. In every other respect, the effects of early endotoxin treatment are essentially the same for both males and females.

The changes in ACTH secretagogue content were also associated with differences in negative-feedback sensitivity to circulating glucocorticoids. Glucocorticoid pretreatment inhibited plasma ACTH responses to stress to a significantly greater extent

Table 1. Mean ( \pm SEM) glucocorticoid receptor binding levels (fmol ${ }^{3} \mathrm{H}$-dexamethasone/mg protein specific binding) in various brain regions in a control and neonatal endotoxin-treated (ENDO) animals $(n=6-8 /$ group $)$

ENDO Control

\begin{tabular}{lcl}
\hline Males & & \\
Hypothalamus & $91.6 \pm 8^{*}$ & $117.0 \pm 8$ \\
Hippocampus & $138.4 \pm 6^{*}$ & $178.9 \pm 14$ \\
Frontal cortex & $142.8 \pm 14^{*}$ & $170.1 \pm 9$ \\
Females & & \\
Hypothalamus & $129.6 \pm 12 \dagger$ & $168.7 \pm 14$ \\
Hippocampus & $150.5 \pm 11^{*}$ & $192.8 \pm 9$ \\
Frontal cortex & $164.3 \pm 9^{*}$ & $195.9 \pm 10$
\end{tabular}

* Significant group differences at $p<0.05$.

$\dagger$ Significant group difference at $0.10>p>0.05$. 
in control than in endotoxin-treated animals. Glucocorticoids are known to regulate the synthesis and release of hypothalamic CRH and AVP (e.g., Hillhouse and Jones, 1976; Plotsky and Vale, 1984; Plotsky et al., 1986; Plotsky and Sawchenko, 1987; Sawchenko, 1987a,b; Owens et al., 1990; Imaki et al., 1991). Indeed, this process is considered as a basis for delayed glucocorticoid negative-feedback effects (see Dallman et al., 1992). Thus, it is possible that the increased synthesis of ACTH secretagogues in the endotoxin-treated animals occurs in response to a decreased tonic, glucocorticoid negative-feedback signal.

The results of the receptor-binding studies provide a potential mechanism for the difference in glucocorticoid feedback sensitivity between control and endotoxin-treated animals. Glucocorticoid receptor density was significantly reduced in the hypothalamus, hippocampus, and frontal cortex of endotoxintreated animals. These structures have been shown to mediate the inhibitory effects of glucocorticoids on (1) $\mathrm{CRH}$ and AVP synthesis in PVN neurons and (2) ACTH release in response to stress (see Feldman and Conforti, 1980; Kovacs and Makara, 1986; McEwen et al., 1986; Sapolsky et al., 1986; Sawchenko, 1987a; Jacobson and Sapolsky, 1991; Dallman et al., 1992; Diorio et al., 1993). Thus, neonatal endotoxin exposure decreases glucocorticoid receptor binding in structures known to mediate glucocorticoid inhibition of HPA activity. These changes in glucocorticoid receptor expression could then represent one way in which early cytokine signals "program" the responsivity of the HPA axis to stress. The decrease in glucocorticoid receptor sites, and thus in glucocorticoid sensitivity, in regions known to govern HPA activity could reduce tonic inhibition of CRH and AVP synthesis, resulting in increased release of ACTH secretagogues in response to stress. This hypothesis suggests that neonatal endotoxin exposure alters HPA responses to stress by influencing the development of glucocorticoid receptor expression in neuronal populations that regulate HPA activity, rather than directly on hypothalamic CRH/AVP neurons.

The mechanisms underlying these effects are not clear; however, it is possible that cytokine release following endotoxin exposure may alter glucocorticoid receptor development. $\mathrm{Nu}-$ merous cytokines (e.g., IL-1, IL-6) are released from various tissues following endotoxin exposure and can cross the bloodbrain barrier (Banks et al., 1993; Muramani et al., 1993; Schobitz et al., 1993). It is interesting that central administration of IL-1 can alter hippocampal glucocorticoid receptor binding in adult animals (Weidenfeld et al., 1988).

In addition, it is interesting that the effects of early endotoxin exposure on HPA development parallel those of maternal separation. Maternal scparation during carly postnatal life results in increased hypothalamic CRH mRNA expression and enhanced HPA responses to stress in adulthood (Plotsky and Meaney, 1993). Although not directly measured, we observed reliable changes in mother-pup interactions following endotoxin administration to neonates. At 3-4 hr postinjection, the dam was consistently off the nest, and this persisted until about $8 \mathrm{hr}$ following treatment. Alterations in maternal behavior likely reflect attempts by the dams to regulate body temperature and avoid tactile contact with pups. Both nest temperature and tactile contact are important factors determining HPA function in neonates (Sucheki et al., 1993) and may have long-term consequences for endocrine function (Stanton et al., 1988). Interestingly, postnatal handling, which seems to increase contact between mother and pups (Jans, Woodside, and Meaney, unpublished observations), results in decreased hypothalamic CRH
mRNA expression and reduced HPA responses to stress (Meaney et al., 1989; Plotsky and Meaney, 1993; Viau et al., 1993). These effects appear to be due to increased glucocorticoid receptor expression in the hippocampus and the frontal cortex (Meaney et al., 1985, 1989; Sarrieau et al., 1988; O'Donnell et al., in press), a pattern exactly opposite to that of early endotoxin exposure. Consequently, factors secondary to the physiological responses to endotoxin exposure may also contribute to the altered HPA development.

These findings suggest that the differentiation of glucocorticoid receptor systems within neural structures that regulate HPA function is sensitive to a variety of environmental signals during the postnatal period. These signals can act to permanently increase or decrease glucocorticoid receptor expression within specific neural structures, and in so doing determine the responsiveness of the HPA axis to stress throughout the lifetime of the animal. We believe that these effects reflect a naturally occurring plasticity whereby the early environment is able to "program" rudimentary, biological responses to threatening stimuli. The activation of the adrenocortical/sympathoadrenal responses to stress is both essential for survival and metabolically very costly. Increased glucocorticoid responses to stress are associated with enhanced immunosuppression (see Munck et al., 1984) and increased risk for neuropathology in later life (Sapolsky et al., 1986; Meaney et al., 1988; Issa et al., 1990). While it is clearly in the animal's best interest to activate these neuroendocrine systems in response to threat, exaggerated or unnecessary activity is also damaging. Hence the importance of an appropriate level of response to the threat. The Norway rat inhabits a tremendous variety of ecological niches, each with varied sets of environmental demands. Wc think that the plasticity observed in these developmental studies allows the animal to adapt defensive systems to the unique demands of the environment. Since mammals usually spend their adult life in an environment that is either the same or quite similar to that in which they were born, developmental "programming" of CNS responses to stress in early life is likely to be of adaptive value to the adult.

The current data represent an interesting example of this process. Under normal conditions, early postnatal life represents a period of bacterial colonization, a time when a previously sterile milieu is inhabited by micro- organisms which are likely to remain as residents throughout the life of the animal. We can assume that there are considerable differences in the degree of colonization as well as in the species and the threat they represent (see Williams et al., 1981). It is also reasonable to assume that these processes as well as the level of pathogens in the environment represent a developmental signal that approximates the level of immunological challenge that is likely to confront the animal over the course of its life. This signal, in turn, appears to be capable of regulating the development of the HPA axis. The HPA axis represents an important regulator of immune function, and Munck et al. (1984) have argued that in the absence of adequate adrenocortical regulation, elevated immune activity can present a cytotoxic threat to the animal. Animals which show inadequate adrenocortical responses to immune challenge are highly vulnerable to autoimmune disorders (see Sternberg et al., 1989) or to the toxic effects of exaggerated immune responses (see Mason et al., 1991). These effects likely involve glucocorticoid production. Following adrenalectomy or treatment with the glucocorticoid receptor antagonist RU 38486, animals are more susceptible to endotoxic shock (Grundmann et al., 1992; Lazar et al., 1992; Ramchandra et al., 1992). In 
this context, the enhanced HPA responsivity of the endotoxintreated animal is probably of adaptive value. What is curious is why (and how) this enhanced level of HPA responsivity becomes generalized to other forms of stress, and this may represent the biological cost extracted from the animal in anticipating (and adapting to) a higher level of immunological challenge. Seen in this light, it is clear that the endotoxin-treated animals in the present study (or the nonhandled animals in earlier research) are not biologically "less fit" than control (or handled) animals: These animals are simply different, and the differences can be at least partially understood in terms of the early environmental events.

\section{References}

Ader R, Grota LJ (1969) Effects of early experience on adrenocortical reactivity. Physiol Behav 4:303-305.

Anisman H, Zalcman S, Zacharko RM (1993) The impact of stressors on immune and central neurotransmitter activity: bidirectional communication. Rev Neurosci 4:147-180.

Banks WA, Kastin AJ, Gutierrez EJ (1993) Intcrlcukin-1 alpha in blood has access to cortical brain cells. Neurosci Lett 163:41-44.

Berkenbosch F, Wolvers DAW, Derijk R (1991) Neuroendocrine and immunological mechanisms in stress-induced immunomodulation. J Steroid Biochem Mol Biol 40:639-647.

Bhatnagar S, Shanks N, Meaney MJ (1992) Central glucocorticoid receptors and immune function in chronically stressed handled and nonhandled rats. Soc Neurosci Abstr 18:1008.

Bhatnagar S, Shanks N, Meaney MJ (in press) Hypothalamic-pituitary-adrenal function in chronic, intermittently cold stressed handled and nonhandled rats. $J$ Neuroendocrinol, in press.

Blalock JE (1984) The immune system as a sensory organ. J Immunol 132:1067-1070.

Bradford M (1976) A rapid and sensitive method for quantitation of microgram quantities of protein utilizing the principle of protein-dyc binding. Anal Biochem 72:248-254.

Chrousos GP, Gold PW (1992) The concepts of stress and stress system disorders. J Am Med Assoc 267:1244-1252.

Dallman MF, Akana SF, Scribner KA, Bradbury MJ, Walker C-D, Strack AM, Cascio CS (1993) Stress, feedback and facilitation in the hypothalamo-pituitary-adrenal axis. J Neuroendocrinol 4:517526.

Diorio D, Viau V, Meaney MJ (1993) The role of the medial prefrontal cortex (cingulate gyrus) in the regulation of hypothalamic-pituitaryadrenal responses to stress. J Neurosci 13:3839-3847.

Dunn AJ, Powell ML, Moreshead WV, Gaskin JM, Hall NR (1987) Effects of Newcastle disease virus administration to mice on the metabolism of cerebral biogenic amines, plasma corticosterone, and lymphocyte proliferation. Brain Behav Immunol 1:216-230.

Dunn AJ, Powell ML, Meitin C, Small PA (1989) Virus infection as a stressor: influenza virus elevates plasma concentrations of corticosterone, and brain concentrations of MHPG and tryptophan. Physiol Behav 45:591-594.

Feldman S, Conforti N (1980) Participation of the dorsal hippocampus in the glucocorticoid feedback effect on adrenocortical activity. Neuroendocrinology 30:52-61.

Gala RR, Westphal U (1965) Corticosteroid-binding globulin in the rat: studies on the sex difference. Endocrinology 77:841-851.

Gillies GE, Linton EA, Lowry PJ (1984) Corticotropin releasing activity of the new CRF is potentiated several times by vasopressin. Nature 299:355-357.

Grundmann HJ, Hanle U, Hegenscheid B, Sahlmuller G, Bienzle U, Blitstein-Willinger E (1992) Inhibition of endotoxin-induced macrophage tumor necrosis factor expression by prostacyclin analogue and its beneficial effect in experimental lipopolysaccharide intoxication. J Infect Dis 165:501-505.

Hess JL, Denenberg VH, Zarrow MX, Pfeifer WD (1969) Modification of the corticosterone response curve as a function of handling in infancy. Physiol Behav 4:109-112.

Hillhouse EW, Jones MT (1976) Effect of bilateral adrenalectomy and corticosteroid therapy on the secretion of corticotrophin-releasing factor activity from the hypothalamus of the rat in vitro. J Endocrinol $71: 21-30$
Hiroshige T, Wada-Okada S (1973) Diurnal changes of hypothalamic content of corticotropin-releasing activity in female rats at various stages of the estrous cycle. Neuroendocrinology 12:316-319.

Imaki T, Nahan J-L, Rivier C, Sawchenko PE, Vale W (1991) Differential regulation of corticotropin-releasing factor $m R N A$ in rat brain regions by glucocorticoids and stress. J Neurosci 11:585-599.

Irwin M, Vale W, Rivier C (1990) Central corticotropin-releasing factor mediates the suppressive effect of stress on natural killer cytotoxicity. Endocrinology 126:2837-2844.

Issa A, Rowe W, Gauthier S, Meaney MJ (1990) Hypothalamic-pituitary-adrenal function in aged, cognitively impaired and unimpaired rats. J Neurosci 10:3247-3254.

Jacobson L, Sapolsky RM (1991) The role of the hippocampus in feedback regulation of the hypothalamic-pituitary-adrenal axis. Endocrinol Rev 12:118-133.

Kovacs K, Kiss JZ, Makara GB (1986) Glucocorticoid implants around the hypothalamic paraventricular nucleus prevent the increase of corticotropin-rclcasing factor and arginine vasopressin immunostaining induced by adrenalectomy. Neuroendocrinology 44:229-234.

Krey LC, Lu K, Butler W, Hotchkiss J, Piva F, Knobil E (1975) Surgical disconnections of the medial basal hypothalamus and pituitary function in the rhesus monkey. II. GH and cortisol secretion. Endocrinology 96:1088-1096.

Lazar G Jr, Duda E, Lazar G (1992) Effect of RU 38486 on TNF production and toxicity. Fed Eur Biochem Soc 308:137-140.

Le Mevel JC, Abitbol S, Beraud G, Maniey J (1979) Temporal changes in plasma adrenocorticotropin concentration after repeated neurotropic stress in male and female rats. Endocrinology 105:812-817.

Levine S (1957) Infantile experience and resistence to physiological stress. Science 126:405-406.

Levine S (1962) Plasma-free corticosteroid response to electric shock in rats stimulated in infancy. Science 135:795-796.

Levine S, Haltmeyer GC, Karas GG, Denenberg VH (1967) Physiological and behavioral effects of infantile stimulation. Physiol Behav 2:55-63.

Linton EA, Tilders FJH, Hodgkinson S, Berkenbosch F, Vermes I, Lowry PJ (1985) Stress-induced secretion of adrenocorticotropin in rats is inhibited by antisera to corticotropin-releasing factor and vasopressin. Endocrinology 116:966-970.

Martin CE, Cake MH, Hartmann PE, Cook IF (1975) Relationship between foetal corticosteroids, maternal progesterone, and parturition in the rat. Acta Endocrinol 84:167-176.

Mason D (1991) Genetic variation in the stress response: susceptibility to experimental allergic encephalomyelitis and implications for human inflammatory disease. Immunol Today 12:57-60.

McEwen BS, Steller E (1993) Stress and the individual: mechanisms leading to disease. Arch Intern Med 153:2093-2101.

McEwen BS, De Kloet ER, Rostene WH (1986) Adrenal steroid receptors and actions in the nervous system. Physiol Rev 66:11211150.

Meaney MJ, Aitken DH, Bodnoff SR, Iny LJ, Tatarewicz JE, Sapolsky RM (1985) Early, postnatal handling alters glucocorticoid receptor concentrations in selected brain regions. Behav Neurosci 99:760-765.

Meaney MJ, Aitken DH, Sapolsky RM (1987) Thyroid hormones influence the development of hippocampal glucocorticoid receptors in the rat: a mechanism for the effects of postnatal handling on the development of the adrenocortical stress response. Neuroendocrinology 45:278-283.

Meaney MJ, Aitken DH, Bhatnagar S, Van Berkel C, Sapolsky RM (1988) Postnatal handling attenuates neuroendocrine, anatomical, and cognitive impairments related to the aged hippocampus. Science 238:766-768.

Meaney MJ, Aitken DH, Sharma S, Viau V, Sarrieau A (1989) Postnatal handling increases hippocampal glucocorticoid receptors and enhances adrenocortical negative-feedback efficacy in the rat. Neuroendocrinology 50:597-604.

Meaney MJ, Mitchell JB, Aitken DH, Bhatnagar S, Bodnoff SR, Iny LJ, Sarrieau A (1991) The effects of neonatal handling on the development of the adrenocortical response to stress: implications for neuropathology and cognitive deficits in later life. Psychoneuroendocrinology 16:85-103.

Meaney MJ, Aitken DH, Sharma S, Viau V (1992) Basal ACTH, corticosterone, and corticosterone-binding globulin levels over the diurnal cycle, and hippocampal type I and type II corticosteroid re- 
ceptors in young and old, handled and nonhandled rats. Neuroendocrinology 55:204-213.

Meaney MJ, O'Donnell D, Viau V, Bhatnagar S, Sarrieau A, Smythe JW, Shanks N, Walker C-D (1993) Corticosteroid receptors in rat brain and pituitary during development and hypothalamic-pituitaryadrenal (HPA) function. In: Receptors and the developing nervous system (McLaughlin P, Zagon I, eds), pp 163-202. London: Chapman and Hall.

Munck A, Guyre PM, Holbrook NJ (1984) Physiological functions of glucocorticoids in stress and their relations to pharmacological actions. Endocrinol Rev 5:25-44.

Murakami K, Akana S, Dallman MF, Ganong WF (1989) Correlation between the stress-induced transient increase in corticotrophin-releasing hormone content of the median eminence of the hypothalamus and adrenocorticotropic hormone secretion. Neuroendocrinology 49 233-241.

Muramani N, Fukata J, Tsukada T, Kobayashi H, Ebisui H, Seqawa H, Muro S, Imura H, Nakao K (1993) Bacterial lipopolysaccarideinduced expression of interleukin-6 messenger ribonucleic acid in rat hypothalamus, pituitary, adrenal gland and spleen. Endocrinology 133:2574-2577

Nakane T, Aughya T, Kanie N, Hollander CS (1985) Evidence for the role of endogenous corticotropin-releasing factor in cold, ether, immobilization, and a traumatic stress. Proc Natl Acad Sci USA 82: 1247-1251.

O'Donnell D, Larocque S, Seckl JR, Meaney MJ (submitted) Postnatal handling alters glucocorticoid, but not mineralocorticoid mRNA expression in adult rats. Mol Brain Res, submitted.

O'Grady MP, Hall NRS (1991) Long-term effects of neuroendocrineimmune interactions during early development. In: Psychoneuroimmunology, Second Edition (Ader R, Felten DL, Cohen N, eds), pp 561-572. San Diego: Academic.

Owens MJ, Bartolome J, Schanberg SM, Nemeroff CB (1990) Corticotropin-releasing factor concentrations exhibit an apparent diurnal rhythm in hypothalamic and extrahypothalamic brain regions: differential sensitivity to corticosterone. Neuroendocrinology 52:626631.

Partridge WM, Sakiyama R, Judd HL (1983) Protein-bound corticosterone in human serum is selectively transported into rat brain and liver in vivo. J Clin Endocrinol Metab 57:160-166.

Pierpaoli W (1981) Integrated phylogenetic and ontogenetic evolution of neuroendocrine and identity-defense, immune functions. In: Psychoneuroimmunology (Ader R, Cohen N, eds), pp 575-607. San Diego: Academic.

Plotsky PM, Meaney MJ (1993) Early, postnatal experience alters hypothalamic corticotropin-releasing factor (CRF) mRNA, median eminence CRF content and stress-induced release in adult rats. Mol Brain Res 18:195-200.

Plotsky PM, Sawchenko PE (1987) Hypophysial-portal plasma levels, median eminence content and immunohistochemical staining of corticotropin releasing factor, arginine vasopressin and oxytocin following pharmacological adrenalectomy. Endocrinology 120:1361-1369.

Plotsky PM, Vale W (1984) Hemorrhage-induced secretion of corticotropin-releasing factor-like immunoreactivity into rat hypophysial portal circulation and its inhibition by glucocorticoids. Endocrinology 114:164-169.

Plotsky PM, Bruhn TO, Vale W (1985) Evidence for multifactor regulation of the adrenocortical secretory response to hemodynamic stimuli. Endocrinology 116:633-639.

Plotsky PM, Otto S, Sapolsky RM (1986) Inhibition of immunoreactive corticotropin-releasing factor secretion into the hypohysial-portal circulation by delayed glucocorticoid feedback. Endocrinology 119: 1126-1130.

Ramchandra RN, Sehon A, Berczi I (1992) Neuro-hormonal defense in endotoxin shock. Brain Behav Immunol 6:157-169.

Reul JMHM, de Kloet ER (1985) Two receptor systems for corticosterone in rat brain: microdistribution and differential occupation. Endocrinology 117:2505-2510.

Rivier C, Stenzel-Poore M, Rivest S, Lee S (1993) Effects of peripheral and central cytokines on the HPA axis of the rat. Ann NY Acad Sci 697 :

Sapolsky RM, Krey LC, McEwen BS (1986) The neuroendocrinology of stress and aging: the glucocorticoid cascade hypothesis. Endocr Rev 7:284-301.

Sapolsky RM, Armanini MP, Packan DR, Sutton SW, Plotsky PM
(1990) Glucocorticoid feedback inhibition of adrenocorticotropic hormone secretagogue release: relationship to corticosteroid receptor occupancy in various limbic sites. Neuroendocrinology 51:328-336.

Sarrieau A, Sharma S, Meaney MJ (1988) Postnatal development and environmental regulation of hippocampal glucocorticoid and mineralocorticoid receptors in the rat. Dev Brain Res 43:158-162.

Sawchenko PE (1987a) Evidence for a local site of action for glucocorticoids in inhibiting CRF and vasopressin expression in the paraventricular nucleus. Brain Res 403:213-224.

Sawchenko PE (1987b) Adrenalectomy-induced enhancement of CRF and vasopressin immunoreactivity in parvocellular neurosecretory neurons: anatomic, peptide, and steroid specificity. J Neurosci 7:10931106.

Schobitz B, Van Den Dobblesteen M, Holsboer F, Sutanto W, De Kloet ER (1993) Regulation of interleukin-6 gene expression in rat. Endocrinology 132:1569-1576.

Shanks N, Griffiths J, Zalcman S, Zacharko RM, Anisman H (1990) Mouse strain differences in plasma corticosterone following uncontrollable footshock. Pharmacol Biochem Behav 36:515-519.

Shanks N, LaRocque S, Meaney MJ (in press a) Hypothalamic-pituitary-adrenal responses to endotoxin challenge in neonatal rats: mediation via CRH. J Neuroendocrinol, in press.

Shanks N, McCormick CM, Meaney M.J (in press b) Sex differences in HPA responses to endotoxin challenge in the neonate: reversal by gonadectomy. Dev Brain Res, in press.

Stanton M, Gutierrez YR, Levine S (1988) Maternal deprivation potentiates pituitary-adrenal stress responses in infant rats. Behav Neurosci 102:692-700.

Stenzel-Poore M, Vale WW, Rivier C (1993) Relationship between antigen-induced immune stimulation and activation of the hypothalamic-pituitary-adrenal axis in the rat. Endocrinology 132:1313-1318.

Sternberg EM, Young WS Jr, Bernardini R (1989) A central nervous defect in the stress response is associated with susceptibility to streptococcal cell wall arthritis in Lewis rats. Proc Natl Acad Sci USA 86: 2374-2378.

Suchecki D, Rosenfeld P, Levine S (1993) Maternal regulation of the hypothalamic-pituitary-adrenal axis in the infant rat: the roles of feeding and stroking. Dev Brain Res 75:185-192.

Suda T, Tomori N, Tozawa F, Mouri T, Demura H, Shizume K (1983) Effects of bilateral adrenalectomy on immunoreactive corticotropinreleasing factor in the rat median eminence and intermediate-posterior pituitary. Endocrinology 113:1182-1184.

Viau V, Meaney MJ (1991) Variations in the hypothalamic-pituitaryadrenal response to stress during the estrus cycle in the rat. Endocrinology 129:2503-2511.

Viau V, Meaney MJ (in press) Androgen regulation of hypothalamicpituitary-adrenal responses to stress in male rats: role of the medial preoptic area. J Neurosci, in press.

Viau V, Sharma S, Plotsky PM, Meaney MJ (1993) The hypothalamicpituitary-adrenal response to stress in handled and nonhandled rats: differences in stress-induced plasma ACTH secretion are not dependent upon increased corticosterone levels. J Neurosci 13:1097-1105.

Walker C-D, Rivest R, Meaney MJ, Aubert ML (1989) Differential activation of the pituitary-adrenocortical axis after stress in the rat: use of two genetically selected lines (Roman low- and high-avoidance rats) as a model. J Endocrinol 123:477-485.

Walker C-D, Akana SF, Cascio CS, Dallman MF (1990) Adrenalectomy in the neonate; adult-like adrenocortical system responses to both removal and replacement of corticosterone. Endocrinology 127 : 832-842.

Watts AG, Swanson LW (1989) Diurnal variations in the content of preprocorticotropin-releasing hormone messenger RNA in the hypothalamic paraventricular nucleus of rats of both sexes as measured by in situ hybridization. Endocrinology 125:1734-1738.

Weidenfeld T, Abramsky O, Ovadia H (1989) Effect of interleukin-1 on ACTH and corticosterone secretion in dexamethasone and adrenalectomized pretreated male rats. Neuroendocrinology 50:650-654.

Williams RF (1981) Colonisation of the developing body by bacteria. In: Scientific foundations of paediatrics (Davis JA, Dobbing J, eds), pp 1045-1065. London: Heinemann.

Witek-Janusek L (1988) Pituitary-adrenal response to bacterial endotoxin in developing rats. Am J Physiol 18:E525-E530.

Zaicman S, Shanks N, Anisman H (1991) Changes in central norepinepherine alterations associated with antigen administration. Brain Res 557:69-76. 